\title{
Analysis of the Effect of Uncertain Renewable Sources on Static Voltage Stability by Using NR-Based DSOPF Model with Adapted IEEE- 30 Bus Test System
}

\author{
B. Baydar, H. Gozde, and M.C. Taplamacioglu
}

\begin{abstract}
This study examines the uncertainty effect of renewable energy resources on the static voltage stability thanks to modeling a specific area of Turkish electricity network by using classic IEEE 30-bus test system. For this purpose, the classic IEEE 30-bus test system is adapted to the Turkish electricity network by using new approach proposed in the study, which is based on the 2015 Turkey real and reactive load curves. In this way, the classic IEEE 30-bus test system is considered a part of Turkish electricity network. The analyses are performed on this model using NewtonRaphson (NR) solution by established three Optimal Power Flow (OPF) studies: dynamic-OPF study without renewable sources, dynamic-OPF study with renewable energy sources having constant power output, Dynamic-Stochastic Optimal Power Flow (DSOPF) study with uncertain renewable energy sources. To take into account the uncertainty effects, Weibull Probability Distribution Function (PDF) using Turkey wind and solar data are used for each month. At the end of the study, it is observed that the integration of uncertain renewable energy sources into the Turkey electricity power system largely decreases both the yearly total generation cost and the reactive power generation.
\end{abstract}

Index Terms-Optimal power flow, Renewable energy sources, Static voltage stability, Uncertainty effect, Weibull probability distribution function.

\section{INTRODUCTION}

$\mathrm{R}$ ENEWABLE ENERGY SOURCES are increasing day by day the share of world electricity energy production in total installed capacity. The remaining 100-150 years of life of fossil-based energy reserves and the serious and now irreversible damages of climate change and global warming impacts that our world faces due to their use are compelling reasons for this increase.

B. BAYDAR, is with Baskent Electricity Distribution Company, EnerjiSA, Ankara, Turkey, (e-mail: basar.baydar@baskentedas.com.tr).

H. GOZDE, is with Department of Electronics and Communication Engineering, National Defence University, Military Academy, Ankara, Turkey, (e-mail: hgozde@kho.edu.tr).

M. C. TAPLAMACIOGLU, is with Department of Electrical and Electronics Engineering University of Gazi, Ankara, Turkey,

(e-mail: taplam@gazi.edu.tr).

Manuscript received May 14, 2018; accepted June 21, 2018. DOI: $\underline{10.17694 / \text { bajece.423459 }}$
Additionally, the use of renewable energy sources as much as possible in electricity generation is also a necessity in terms of reducing the cost of electricity energy consumption which is rapidly increasing in parallel with developing technology. In theory; it is clear that the use of renewable energy sources with a source nature of almost zero cost instead of relatively costly power plants such as fossil-fueled natural gas plants that are commissioned to meet additional demand at peak times in a continuously changing supply-demand balance will greatly reduce electricity energy consumption prices. Practically, this is proved by the countries that increase the use of renewable energy. For example; It was reported that the price of electricity in Germany has been about $80 € / \mathrm{MWh}$ in peak hours in 2008 and it has been decreased to $38 € / \mathrm{MWh}$ in 2013 with the increase in renewable energy plants [1]. In parallel with these factors, the share of renewable energy sources in the world electricity energy production was determined as 21\% in 2015. It has been estimated to be around $30 \%$ in 2035. In 2016, the world's net capacity additions obtained from renewable energy sources was around $66 \%$, while the installed capacities of the coal and gas power plants declined in the same year [2]. In terms of net capacity increase, solar energy power plants rose for the first time in the world with an increase of $75 \mathrm{GW}$ for the first time [3]. Similarly, the proportion of renewable energy sources in the net additional capacity in Turkey was 55\% in 2016. By the end of 2017, the total installed capacity of renewable energy plants in Turkey has reached approximately $39 \mathrm{GW}$ [4]. It is planned to increase this power to $60 \mathrm{GW}$ by 2023. In this regard, it is planed that worldwide until 2030, $\mathrm{CO}_{2}$ emission from fossil-based electricity generation plants will be reduced by $40 \%$ [3].

Whereas; the increase in the proportion of renewable power plants in total installed capacity brings some problems affecting the power quality of the countries in the electricity grid and the interconnected system. It is possible to divide these problems in general into the problems related to integration and stability. It can be said that the integration problems are mostly related to the infrastructure competencies of the distribution and transmission networks of the countries. For example, the active and reactive power capacity competencies of the transformer substations in the distribution network include the basic factors such as the availability of transformer substations with sufficient short circuit power capacity in the region according 
to the capacity of the renewable plant to be connected and the active and reactive power carrying capacities of the respective transmission lines. The solutions of these problems depend on the countries' midterm and long-term electricity infrastructure improvement, renewal and expansion plans. On the other hand, the stability problems can be caused from both the power network and the renewable power plant itself. It is clear that the uncertain nature of the renewable resources is the most effective reason of these problems. In literature, the uncertainty effect of the renewable resources to the power network has been examined so far by using different OPF models. It is known that the classic OPF analysis provides only instant information about the power system. To reach the more realistic long-term results, the analyses are spread periodically throughout months, years etc. by using dynamic-OPF analysis. In addition, these long-term dynamic-OPF analyses are improved to the stochastic-dynamic OPF by taking into account uncertainties of the process. At the recent ones, Liang et al. presented a widearea measurement based DSOPF algorithm using the adaptive critic design (ACD) technique in 2012 [5]. In 2014, Gill et al. proposed the dynamic-OPF analysis for active distribution power system [6]. Two years after, Wei et al. proposed an integration technique of DG based on stochastic OPF model [7]. At the same year, Sun et al. proposed a DSOPF for wind farms and EVs integrated power system based on the chanceconstrained programming model [8], then Bai et al. were aimed to reduce the expected operational cost by using 94 wind power plants in Texas developed with raw data and using the model to estimate hourly wind energy outputs for 24 hours [9]. In 2017, in his doctoral dissertation, Bai utilized a probabilistic forecast model, dynamic factor model (DFM), to predict wind power. This work also focuses on the optimization of the system integrated with wind power and storage devices over 24 hours. In this doctoral dissertation, has been tested on small, medium and large power system for OPF (IEEE-30, IEEE-57 and IEEE118 buses) and then it was modified and extended to solve a dynamic optimization problem recursively [10].

This study examines the uncertainty effect of renewable energy resources on the static voltage stability is examined thanks to modeling a specific area of Turkish electricity network by using IEEE 30-bus test system. For this purpose, IEEE 30-bus test system is adapted to the Turkish electricity network by using new approach proposed in the study, which is based on the 2015 Turkey real and reactive load curves obtained from TEIAS for the year of 2015 for Turkey. In this way, IEEE 30-bus test system is considered a part of Turkish electricity network. The analyses are performed on this model by established three OPF studies: dynamic-OPF study without renewable sources, dynamic-OPF study with renewable energy sources having constant power output, DSOPF study with uncertain renewable energy sources. All models have contained IEEE 30-bus test system arranged monthly in accordance with these load curves. The behavior of modified IEEE 30-bus system has been examined only at the first model for being reference. The renewable power plants have been integrated to this model in the second one. Finally, the third model has been composed to include the uncertainty of the renewable resources. To take into account the uncertainty effects, Weibull probability distribution function using Turkey wind and solar data are used for each month.
This article is organized as follows; the OPF problem and the new OPF models are summarized in Section II. Proposed OPF models are explained in Section III. The case studies for examinations are presented and discussed in Section IV and they are concluded in the Conclusion section.

\section{OPTIMAL POWER FLOW PROBLEM}

The Optimal Power Flow (OPF) was first introduced by Carpentier in 1962 [11]. It is defined as the production sharing of optimal power exchange between generators and barriers in production, without exceeding the physical limits of the equipment used in the power systems. Actually, OPF is a nonlinear optimization problem including a flow which must be optimized, a desired equality, inequality constraint, and a problem solving method $[12,13]$. In other words, the OPF optimizes a certain the power flow within an electrical power system without violating power flow restrictions and operational limits $[14,15]$. Conclusively, it maximizes the energy quality and determines the optimal working condition for the power system.

The general OPF problem is formulated in Equation 1 [16]:

$f(x, u)=0-$ is objective function

$g(x, u)=0$ - is equality constraints

$h(x, u) \leq 0-$ is inequality constraints

Where:

$f(x, u)$ - is the minimization function to optimize the solution, $g(x, u)$ - represents the power flow equations,

$h(x, u)$ - represents the power system safety limits, $x, u$ - are the status and control variables, respectively.

The state variables of the power system are the real output power of the slack bus, the voltage amplitudes of the load buses and the reactive output powers of the generator buses as depicted in Equation (2):

$x=\left[P_{\text {slack }}, V_{L}, Q_{g}\right]$

The control variables include the real output powers of the generator buses except slack bus, voltage magnitudes of the generator buses, transformer tap-changes and shunt capacities as represented in Equation (3):

$u=\left[P_{g}, V_{g}, T, Q_{c}\right]$

The general cost function $F_{\text {cost }}$ in order to minimize the entire production cost of the power system can be determined as Equation (4):

$F_{\text {yakla }}=\sum_{i=1}^{N_{g}}\left(\alpha_{i}+\beta_{i} \cdot P_{g i}+\gamma_{i} \cdot P_{g i}^{2}\right)$

Where:

$N_{g}$ - is the number of generators in the power system,

$P_{g i}-$ is the real powers of the generators,

$\alpha_{i}, \beta_{i}$ and $\gamma_{i}$-are the generator fuel cost coefficients.

Finally, the real and reactive power at bus $k$ from the system can be given as Equation (5) and Equation (6): 
$\mathrm{P}_{\mathrm{k}}=0=\mathrm{V}_{\mathrm{k}} \sum_{\mathrm{m}=1}^{\mathrm{N}}\left[\mathrm{V}_{\mathrm{m}} \cdot\left[\mathrm{g}_{\mathrm{km}} \cdot \cos \left(\delta_{\mathrm{k}}-\delta_{\mathrm{m}}\right)+\mathrm{b}_{\mathrm{km}} \cdot \sin \left(\delta_{\mathrm{k}}-\delta_{\mathrm{m}}\right)\right]-\mathrm{P}_{\mathrm{GK}}+\mathrm{P}_{\mathrm{LK}}\right.$

$Q_{k}=0=V_{k} \sum_{m=1}^{N}\left[V_{m} \cdot\left[g_{k m} \cdot \sin \left(\delta_{k}-\delta_{m}\right)-b_{k m} \cdot \cos \left(\delta_{k}-\delta_{m}\right)\right]\right]-Q_{G K}+Q_{L K}$

The required limits generator real power, generator reactive power, bus voltage magnitude, transformer tap-changing value and shunt capacity can be arranged according to the nature of the application.

On the other hand the OPF problem has been extended to the different OPF models according to solution requirements, especially for renewable energy sources with uncertainty. Some of them are summarized as follows:

Static OPF: Static OPF model defines the classic OPF problem. It can only manage a single load level at a certain time [17].

Dynamic OPF: This OPF model is similar to the static one. The difference is that the dynamic OPF model covers multiple time periods $[18,19]$.

Transient stability-constrained OPF: This problem handles static and dynamic constraints of the power network simultaneously during the optimization process [19]. In this case, the system can withstand serious hazards [20].

Security-constrained $O P F$ : This is another extended version of the OPF which involves constraints arising from the operation of the system under a set of postulated contingencies. SCOPF studies help to overcome when any real contingency happens by rescheduling / controlling to make sure that system is within the allowed limits of operation and termed as steady state security [21].

Deterministic OPF: This derivatization based OPF model does not take into account the stochastic factors. The deterministic OPF is a typical short-term decision-making tool used by a number of utilities and its implementation in this work aims to give a reasonable benchmark for comparison. Traditional deterministic OPF models dispatch controllable generation using the central (most likely) wind forecast, i.e., they do not endogenously account for the variability and uncertainty of wind generation [22].

Stochastic OPF: This type of OPF model takes into account the uncertainties in the power system parameters [23, 24]. Indeed, uncertainty sees it as part of constraints and objective models. For this reason, optimization process and final OPF results may be affected by uncertain factors [25]. These uncertainties can be changes of the wind for a wind turbine.

Probabilistic OPF: Estimates the probability distribution functions of dependent variables based on probability distributions of loads and other indeterminate factors using Monte Carlo Simulation [26], Cumulant method [27], Point Estimation Method (PEM) [28], and adapted Gaussian mixture model [29] uncertain factors do not affect the final results.

$A C$ OPF: The AC OPF model is associated with the AC power network and is based on the natural power flow characteristics of the system [30]. As a result, the results obtained with this type of OPF are more accurate [31].

$D C O P F$ : This type of OPF does not consider reactive power and transmission losses [30].
Mixed AC/DC OPF: Both AC and DC parameters in the power system are associated with OPF [32].

In this study, the dynamic OPF model and the stochastic OPF model are combined with each other in order to examine the effect of uncertain variations at the renewable energy resources to the static stability of the power system as explained below. For this purpose, while the dynamic OPF is modeled in a year period for monthly, the stochastic OPF is modeled with Weibull PDF of sun radiation and wind variation for each the month.

\section{PREPARATION OF DSOPF MODEL}

The IEEE 30-bus test system is used as an example power system in this study [33]. To preparation of the combined DSOPF model, the three regulations explained below have been performed on the IEEE 30-bus test system. In this way, the three OPF model are obtained as;

Model-1: Monthly dynamic OPF model for a year on the IEEE 30-bus test system,

Model-2: Monthly dynamic OPF model for a year on the IEEE 30-bus test system with static renewable sources,

Model-3: Monthly combined DSOPF model for a year on the IEEE-30 bus test system with uncertain renewable sources modeled with Weibull PDF.

After that, the three case studies have been realized using these three models in order to examine the effect of uncertain variations at the renewable energy resources to the static voltage stability of the power system.

\subsection{Regulation-I}

In this regulation, the standard IEEE 30-bus test system is reorganized monthly as a dynamic OPF model according to the real and reactive power load curves of 2015 obtained from the TEIAS annual sector reports [34]. This load curves are represented in Fig. 1.

Turkey's monthly real and reactive power consumption peak values of 2015 obtained from these curves are used to calculate the monthly values of constant total real and total reactive powers for the IEEE 30-bus test system as explained below. For this purpose, the total real and reactive powers of the IEEE 30bus test system replaced with the peak values of the curves for each month.

Real Power $^{\prime}($ Month $)=\frac{\begin{array}{c}\text { Real Power } \\ (\text { Month })\end{array}}{\text { Peak }} \times$ Peak $_{\text {IEEE30 }}$
Reactive Power $($ Month $)=\frac{\text { Reactive }}{\text { Peak }(\text { Month })} \times$ Peak $_{\text {IEEE30 }}$

Sampling for real and reactive power for January, it will be as follows;

$256,7 M W=\frac{6328,2 M W}{6984,2 M W} \times 283,4 M W$
$256,7 M V a r=\frac{1248,9 M V a r}{1400,9 M V a r} \times 126,2 M V a r$ 


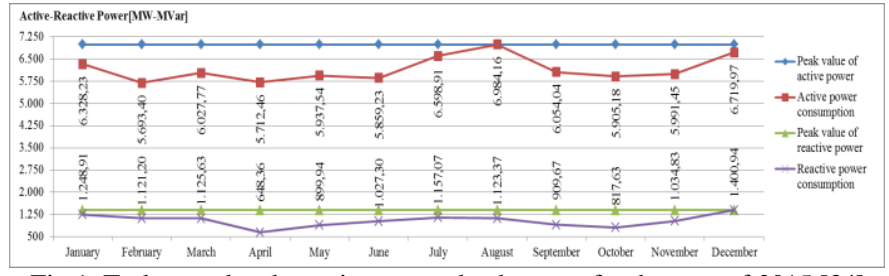

Fig.1. Turkey real and reactive power load curves for the year of 2015 [34]

After that, the load sharing for each bus in the IEEE 30-bus system represented as $\boldsymbol{A}$ can be computed with the equations below;

$A=\frac{\text { Demand in bus }-n \text { (Real or Reactive) }}{\text { Peak (Realor Reactive) }}$

Real power (each month and bus) $=$ Monthly Real Power $x \mathrm{~A}$

Sampling for the $2^{\text {nd }}$ bus for January;

$0,07657=\frac{21,7 M W}{283,4 M W}$

$19,66 M W=256,7 M W x 0,07657$

The load curves of the monthly total real and reactive powers for the Model-1 is represented in Fig. 2 and Fig. 3;

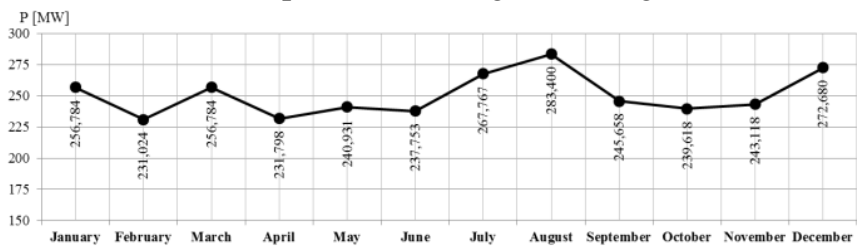

Fig.2. Monthly total real power load curve for Model-1

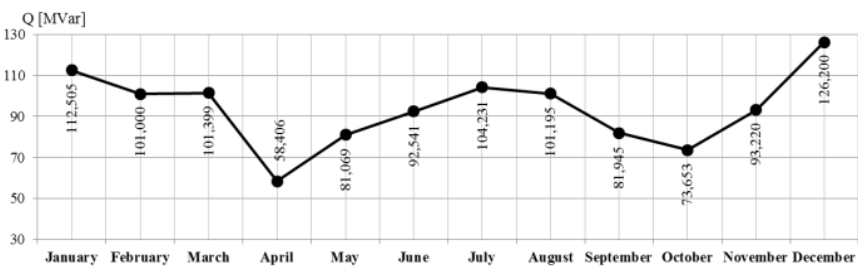

Fig.3. Monthly total reactive power load curve for Model-1.

\subsection{Regulation-II}

The renewable energy sources are integrated into Model-1 in the rate of $48 \%$ of total capacity by modifying the bus-5 and bus-11 as the wind power plants and bus-13 as the solar power plants in IEEE 30-bus standard test system. The single-line diagram of the modified IEEE 30-bus system for Model-2 (also for Model-3) and new generation capacities of the power plants are represented in Fig. 4 and Table 1.

TABLE I

GENERATION CAPACITIES OF THE MODEL-2 [35]

\begin{tabular}{|c|c|c|}
\hline Bus No & Plant Type & Generation Capacity, [MW] \\
\hline 1 & Thermal & 99.248 \\
\hline 2 & Thermal & 80.000 \\
\hline 5 & Wind & 75.000 \\
\hline 8 & Thermal & 20.000 \\
\hline 11 & Wind & 60.000 \\
\hline 13 & Solar & 50.000 \\
\hline
\end{tabular}

After this modification, the new load curves as a dynamic OPF model are computed as similar to the Regulation- 1 .

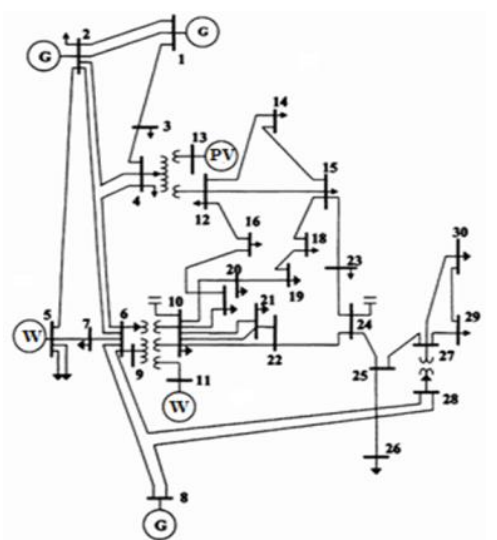

Fig.4. Modified IEEE 30-bus system for Model-2 and Model-3

\subsection{Regulation-III}

This regulation is realized to compose Model-3. In this regulation, dynamic and stochastic OPF models are combined with each other as DSOPF in order to examine the uncertainty of the renewable energy resources integrated to the Model-2. The stochastic OPF model is achieved by using Weibull PDF to model the monthly variations of the wind speed and the sun radiation as explained below.

\subsubsection{Modelling wind speed uncertainty}

To modeling wind speed uncertainty, it is assumed in accordance with the IEEE 30-bus standard test system layout that the two wind power plants at the bus- 5 and bus- 11 powered $75 \mathrm{MW}$ and $50 \mathrm{MW}$, respectively has been installed in Amasra county of Bartin in Turkey. The chosen values of air density ( $\rho$ $=1,211 \mathrm{~kg} / \mathrm{m}^{3}$ ), scale factor $k$ and shape factor $c$ for Amasra region and the computed values below are represented in Table 2 [36]. The gamma function is used to find the average wind speeds $\left(V_{m}\right)$ for each month. Gamma function is represented in Equation (12).

$V_{m}=c \cdot \Gamma\left(\frac{1}{k}\right)$

TABLE II

$k$ AND $c$ COEFFICIENTS AND COMPUTED RESULTS OF WEIBULL PDF FOR EACH MONTH

\begin{tabular}{|c|c|c|c|c|c|c|}
\hline \multicolumn{7}{|c|}{ Amasra Region $\left(\boldsymbol{\rho = 1 , 2 1 1} \mathbf{~ k g} / \mathbf{m}^{\mathbf{3}}\right)$} \\
\hline Months & $\mathbf{k}$ & $\mathbf{c}$ & $\begin{array}{c}\mathbf{V}_{\mathbf{m}}, \\
{[\mathbf{m} / \mathbf{s}]}\end{array}$ & $\mathbf{f}_{\mathbf{W}}$ & $\mathbf{F}_{\mathbf{w}}$ & $\begin{array}{c}\text { Power } \\
\mathbf{d e n s i t y , ~} \\
{\left[\mathbf{W} / \mathbf{m}^{2}\right]}\end{array}$ \\
\hline January & 1,48 & 8,63 & 7,8037 & 0,0690 & 0,5775 & 287,7522 \\
\hline February & 1,50 & 8,22 & 7,4206 & 0,0735 & 0,5759 & 247,4146 \\
\hline March & 1,54 & 9,81 & 8,8292 & 0,0634 & 0,5727 & 416,7502 \\
\hline April & 1,39 & 7,79 & 7,1081 & 0,0714 & 0,5854 & 217,4564 \\
\hline May & 1,40 & 5,56 & 5,0675 & 0,1008 & 0,5845 & 78,7951 \\
\hline June & 1,40 & 6,10 & 5,5597 & 0,0919 & 0,5845 & 104,0553 \\
\hline July & 1,30 & 7,41 & 6,8437 & 0,0695 & 0,5942 & 194,0831 \\
\hline August & 1,49 & 6,53 & 5,8998 & 0,0919 & 0,5767 & 124,3425 \\
\hline September & 1,82 & 7,11 & 6,3196 & 0,1037 & 0,5538 & 152,8187 \\
\hline October & 1,59 & 8,97 & 8,0470 & 0,0717 & 0,5689 & 315,5100 \\
\hline November & 1,63 & 7,16 & 6,4090 & 0,0921 & 0,5660 & 159,3960 \\
\hline December & 1,94 & 9,57 & 8,4869 & 0,0820 & 0,5471 & 370,1391 \\
\hline
\end{tabular}


The monthly Weibull PDFs of the wind speed for 0-40 m/s range can be computed by using equation (13). The monthly Weibull PDFs are depicted in Fig. 5.

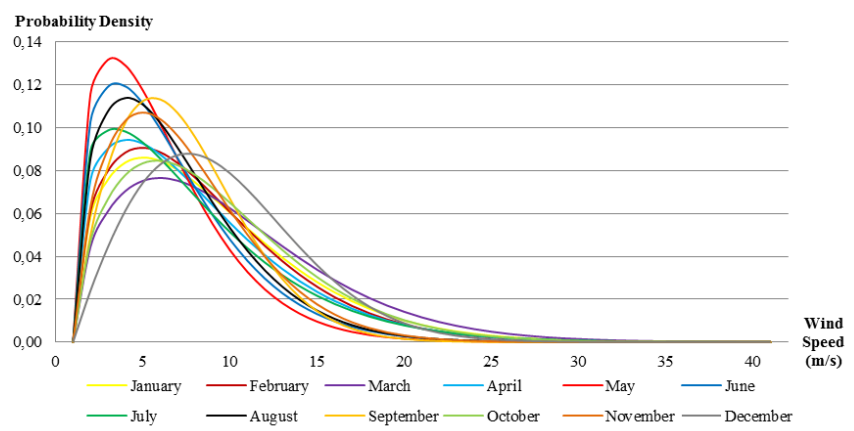

Fig.5. The monthly Weibull PDFs for Model-3

$$
f_{w}(v)=\left(\frac{k}{c}\right) \cdot\left(\frac{v}{c}\right)^{k-1} \cdot e^{\left(-\left(\frac{v}{c}\right)^{k}\right)}
$$

Then, the cumulative Weibull PDFs for each month which give the probability of being less than or equal to the average speed of that month is computed as below;

$F_{w}(v)=1-e^{\left(-\left(\frac{v}{c}\right)^{k}\right)}$

ENERCON E-115 E-2 model $3,200 \mathrm{~kW}$ wind turbine is selected for this study. The cut-in speed $v_{i}$, rated speed $v_{r}$ and cut-out speed $v_{o}$ for the turbine are given in Table 3 . The turbine output power according to the speeds are calculated and presented at the same table.

$p=\left\{\begin{array}{lr}0, & v \leq v_{i}, v>v_{0} \\ p_{r}\left(\frac{v-v_{i}}{v_{r}-v_{i}}\right), & v_{i} \leq v \leq v_{r} \\ p_{r}, & v_{r} \leq v \leq v_{0}\end{array}\right.$

TABLE III

THE CUT-IN SPEED $V_{i}$, RATED SPEED $V_{R}$, AND CUT-OUT SPEED $V_{O}$ FOR THE TURBINE

\begin{tabular}{|c|c|c|c|c|c|c|}
\hline Months & $\begin{array}{c}\mathbf{v}, \\
{[\mathbf{m} / \mathbf{s}]}\end{array}$ & $\begin{array}{c}\mathbf{v}_{\mathbf{i}}, \\
{[\mathbf{m} / \mathbf{s}]}\end{array}$ & $\begin{array}{c}\mathbf{v}_{\mathbf{r}}, \\
{[\mathbf{m} / \mathbf{s}]}\end{array}$ & $\begin{array}{c}\mathbf{v}_{\mathbf{o}}, \\
{[\mathbf{m} / \mathbf{s}]}\end{array}$ & $\begin{array}{c}\mathbf{P}_{\text {75Mw, }} \\
{[\mathbf{M W}]}\end{array}$ & $\begin{array}{c}\mathbf{P}_{\text {60Mw, }} \\
{[\mathbf{M W}]}\end{array}$ \\
\hline January & 7,8037 & 2,0000 & 11,0000 & 25,0000 & 48,3643 & 38,6914 \\
\hline February & 7,4206 & 2,0000 & 11,0000 & 25,0000 & 45,1714 & 36,1371 \\
\hline March & 8,8292 & 2,0000 & 11,0000 & 25,0000 & 56,9099 & 45,5279 \\
\hline April & 7,1081 & 2,0000 & 11,0000 & 25,0000 & 42,5674 & 34,0539 \\
\hline May & 5,0675 & 2,0000 & 11,0000 & 25,0000 & 25,5626 & 20,4501 \\
\hline June & 5,5597 & 2,0000 & 11,0000 & 25,0000 & 29,6640 & 23,7312 \\
\hline July & 6,8437 & 2,0000 & 11,0000 & 25,0000 & 40,3642 & 32,2914 \\
\hline August & 5,8998 & 2,0000 & 11,0000 & 25,0000 & 32,4981 & 25,9985 \\
\hline September & 6,3196 & 2,0000 & 11,0000 & 25,0000 & 35,9964 & 28,7971 \\
\hline October & 8,0470 & 2,0000 & 11,0000 & 25,0000 & 50,3915 & 40,3132 \\
\hline November & 6,4090 & 2,0000 & 11,0000 & 25,0000 & 36,7414 & 29,3931 \\
\hline December & 8,4869 & 2,0000 & 11,0000 & 25,0000 & 54,0577 & 43,2462 \\
\hline
\end{tabular}

\subsubsection{Modelling solar radiation uncertainty}

To modeling solar radiation uncertainty, it is assumed in accordance with the IEEE 30-bus standard test system layout that the solar power plants at the bus-13 powered $50 \mathrm{MW}$ has been installed in Ankara region in Turkey. The model of the solar power plant can be obtained with the direct normal radiation values calculated for this region. For this region, DNI (Direct Normal Irradiation) values depicted in Fig. 6 which are directly calculated instead of the $k$ and $c$ parameters are used [36].

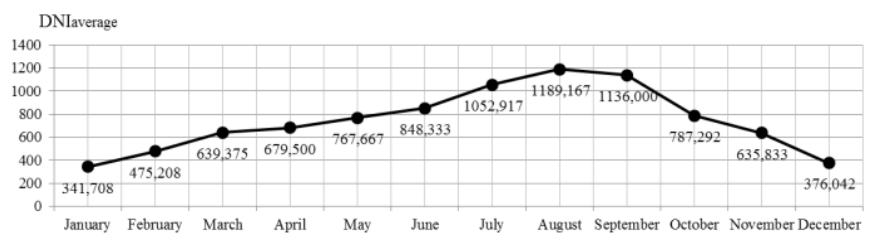

Fig.6. Average monthly DNI values for Ankara region [34]

The AXITECAC 320P/156-72S model solar panels are selected for this study. The PV panel output power according to the amount of solar radiation is calculated as below [34]. These values are shown in Table 4 for each month.

$P_{P V}(G)=\left\{\begin{array}{rr}P_{s r}\left(\frac{G^{2}}{G_{s t d} \cdot R_{c}}\right) & 0<G<R_{c} \\ P_{s r}\left(\frac{G}{G_{s t d}}\right) & G>R_{c}\end{array}\right.$

Where:

$G$ - is solar irradiance forecast

$G_{\text {std }}$ - is standard irradiation $\left[1000 \mathrm{~W} / \mathrm{m}^{2}\right]$

$R_{c}$ - is a certain irradiation point set to $150 \mathrm{~W} / \mathrm{m}^{2}$

$P_{s r}$ - is rated equivalent power output of the PV system

TABLE IV

MONTHLY FRACTION OF DNI VALUES FOR ANKARA REGION

\begin{tabular}{|c|c|c|c|c|}
\hline Ankara & $\begin{array}{c}\mathbf{G}, \\
{\left[\mathbf{W} / \mathbf{m}^{2}\right]}\end{array}$ & $\begin{array}{c}\mathbf{G}_{\text {std, }} \\
{\left[\mathbf{W} / \mathbf{m}^{2}\right]}\end{array}$ & $\begin{array}{c}\mathbf{R}_{\mathbf{c}}, \\
{\left[\mathbf{W} / \mathbf{m}^{2}\right]}\end{array}$ & $\begin{array}{c}\mathbf{P}_{\text {50Mw, }} \\
{[\mathbf{M W}]}\end{array}$ \\
\hline January & 341,7083 & 1000 & 150 & 17,0854 \\
\hline February & 475,2083 & 1000 & 150 & 23,7604 \\
\hline March & 639,3750 & 1000 & 150 & 31,9688 \\
\hline April & 679,5000 & 1000 & 150 & 33,9750 \\
\hline May & 767,6667 & 1000 & 150 & 38,3833 \\
\hline June & 848,3333 & 1000 & 150 & 42,4167 \\
\hline July & 1052,9167 & 1000 & 150 & 52,6458 \\
\hline August & 1189,1667 & 1000 & 150 & 59,4583 \\
\hline September & 1136,0000 & 1000 & 150 & 56,8000 \\
\hline October & 787,2917 & 1000 & 150 & 39,3646 \\
\hline November & 635,8333 & 1000 & 150 & 31,7917 \\
\hline December & 376,0417 & 1000 & 150 & 18,8021 \\
\hline
\end{tabular}

\section{PROPOSED OpF STUDIES}

To examine the uncertainty effect of the renewable energy sources added to the IEEE 30-bus system in according to regulations considered before, three cases are performed by using model-1, model-2 and model-3. All OPF problems have been solved by Newton-Raphson solution method on MATLAB environment.

\subsection{Case-I:}

In this case, the dynamic OPF model is applied to the IEEE 30bus test system and only the monthly real and reactive powers 
are changed in each bus. All of the plants are considered thermal power plants.

TABLE V

THE RESULTS OF CASE-I

\begin{tabular}{|c|c|c|c|c|c|}
\hline & $\begin{array}{c}\text { Total } \\
\text { Active } \\
\text { Power, } \\
{[\mathbf{M W}]}\end{array}$ & $\begin{array}{c}\text { Total } \\
\text { Reactive } \\
\text { Power, } \\
{[\text { MVAR] }}\end{array}$ & $\begin{array}{c}\text { Cost, } \\
{[\mathbf{\$} / \mathbf{h}]}\end{array}$ & $\begin{array}{c}\text { Standard } \\
\text { Deviations } \\
\text { of the } \\
\text { Voltage } \\
\text { Magnitudes }\end{array}$ & $\begin{array}{c}\text { Standard } \\
\text { Deviations } \\
\text { of the } \\
\text { Phase } \\
\text { Angles }\end{array}$ \\
\hline January & 264,705 & 74,061 & 707,06 & 0,0165 & 2,8423 \\
\hline February & 237,329 & 55,944 & 618,91 & 0,0157 & 2,5157 \\
\hline March & 264,655 & 62,518 & 706,86 & 0,0157 & 2,8459 \\
\hline April & 238,057 & 14,541 & 620,90 & 0,0150 & 2,5546 \\
\hline May & 247,794 & 37,770 & 651,80 & 0,0144 & 2,6623 \\
\hline June & 244,489 & 49,137 & 641,32 & 0,0157 & 2,6120 \\
\hline July & 276,258 & 68,104 & 745,72 & 0,0165 & 2,9705 \\
\hline August & 292,744 & 68,673 & 802,05 & 0,0166 & 3,1368 \\
\hline September & 252,797 & 39,803 & 667,93 & 0,0145 & 2,7230 \\
\hline October & 246,397 & 29,969 & 647,30 & 0,0146 & 2,6509 \\
\hline November & 250,189 & 51,146 & 659,56 & 0,0158 & 3,0806 \\
\hline December & 281,535 & 91,767 & 763,63 & 0,0176 & 3,0154 \\
\hline & $\mathbf{3 0 9 6 , 9 5}$ & $\mathbf{6 4 3 , 4 3}$ & $\mathbf{8 2 3 3 , 0 4}$ & $\mathbf{0 , 0 1 5 7}$ & $\mathbf{2 , 8 0 0 0}$ \\
$($ total $)$ & $($ total $)$ & $($ total $)$ & (average $)$ & (average $)$ \\
\hline
\end{tabular}

The results obtained by using model- 1 are represented in Table 5. The fuel costs, the voltage magnitudes and the phase angles of the voltages are computed monthly for each bus with dynamic OPF model. However, the voltage magnitudes and their phase angles for each month are represented by computing their standard deviations. At the end of the table, the average values are presented. On the other hand, these values are represented graphically in Fig. 7, 8 and 9.

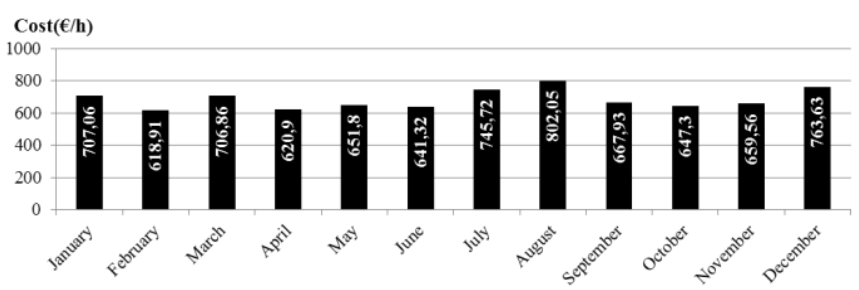

Fig.7. Monthly cost values for case-I

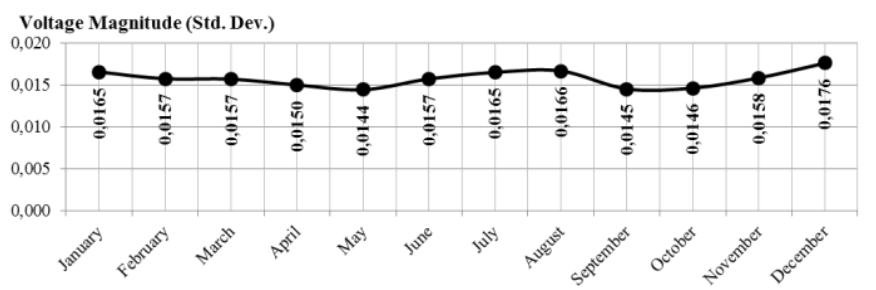

Fig.8. Monthly standard derivations of the voltage magnitudes for case-I

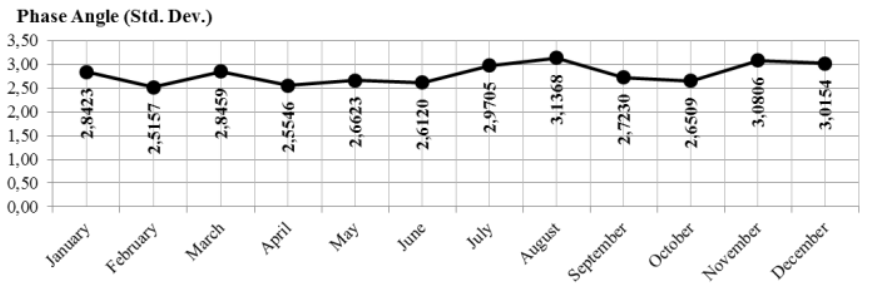

Fig.9. Monthly standard derivations of the voltage angles for case-I

\subsection{Case-II:}

In this case, the dynamic OPF model is applied to the IEEE 30bus test system with the renewable energy sources which have the constant outputs. In this model, bus-5 and bus- 1 considered wind power plants whose capacities are $75 \mathrm{MW}$ and $60 \mathrm{MW}$, respectively. Also, bus-13 is considered $50 \mathrm{MW}$ solar power plant. The other generation buses are considered same as the standard IEEE 30-bus test system. The results obtained by using model-2 are represented in Table 6.

The results are computed monthly for each bus with dynamic OPF model which have renewable power plants having constant power outputs. The coefficients of the quadratic cost function presented in equation (4) are taken zero for the renewable energy sources at this case study since there are no or close to zero fuel costs for renewable power plants in actual in steady-state. For this reason, the costs are computed quite small than the standard ones. The voltage magnitudes and their phase angles for each month are also represented with standard deviations. At the end of the table, the average values are presented. The graphics of these values are depicted in Fig. 10, 11 and 12.

TABLE VI

THE RESULTS OF CASE-II

\begin{tabular}{|c|c|c|c|c|c|}
\hline Months & $\begin{array}{c}\text { Total } \\
\text { Active } \\
\text { Power, } \\
{[\mathbf{M W}]}\end{array}$ & $\begin{array}{c}\text { Total } \\
\text { Reactive } \\
\text { Power, } \\
{[\mathbf{M V A R}]}\end{array}$ & $\begin{array}{c}\text { Cost, } \\
{[\mathbf{\$} / \mathbf{h}]}\end{array}$ & $\begin{array}{c}\text { Standard } \\
\text { Deviations } \\
\text { of The } \\
\text { Voltage } \\
\text { Magnitudes }\end{array}$ & $\begin{array}{c}\text { Standard } \\
\text { Deviations } \\
\text { of The } \\
\text { Phase } \\
\text { Angles }\end{array}$ \\
\hline January & 258,900 & 43,282 & 170,45 & 0,0169 & 2,3862 \\
\hline February & 232,687 & 38,735 & 111,97 & 0,0160 & 2,2954 \\
\hline March & 258,846 & 36,515 & 170,33 & 0,0164 & 2,3861 \\
\hline April & 233,233 & 34,088 & 113,14 & 0,0127 & 2,3365 \\
\hline May & 242,556 & 35,622 & 133,39 & 0,0134 & 2,3535 \\
\hline June & 239,352 & 38,179 & 126,35 & 0,0146 & 2,3099 \\
\hline July & 270,123 & 37,734 & 197,07 & 0,0168 & 2,4440 \\
\hline August & 286,258 & 35,373 & 236,98 & 0,0170 & 2,5409 \\
\hline September & 247,350 & 31,234 & 144,05 & 0,0146 & 2,3371 \\
\hline October & 241,213 & 31,387 & 130,43 & 0,0135 & 2,3497 \\
\hline November & 244,801 & 38,089 & 138,36 & 0,0147 & 2,3276 \\
\hline December & 275,275 & 50,534 & 209,60 & 0,0180 & 2,4719 \\
\hline & $\mathbf{3 0 3 0 , 5 9}$ & $\mathbf{4 5 0 , 7 7}$ & $\mathbf{1 8 8 2 , 1 2}$ & $\begin{array}{c}\mathbf{0 , 0 1 5 3} \\
(\text { total })\end{array}$ & $\begin{array}{c}\mathbf{2 , 3 7 8 2} \\
\text { (average })\end{array}$ \\
\hline (average $)$ \\
\hline
\end{tabular}

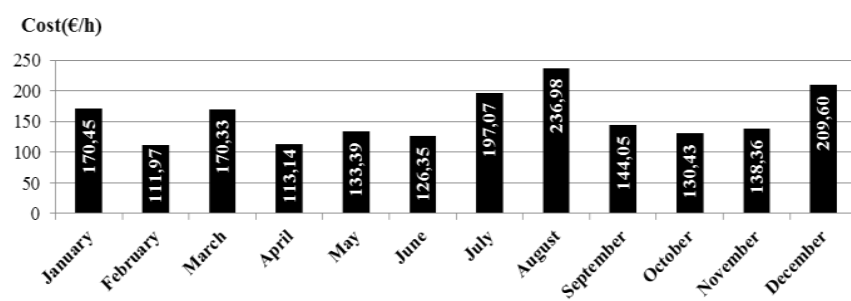

Fig.10. Monthly cost values for case-II

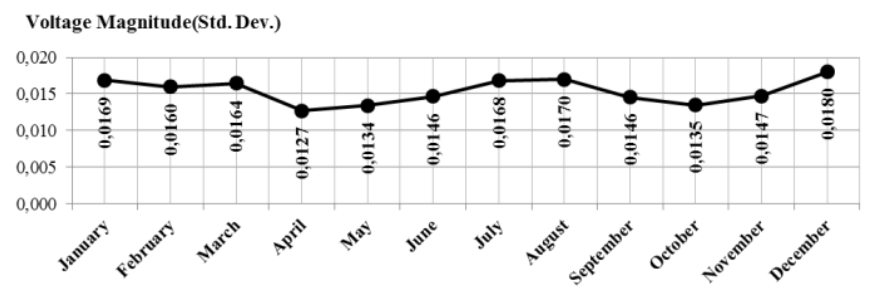

Fig.11. Monthly standard derivations of the voltage magnitudes for case-II 


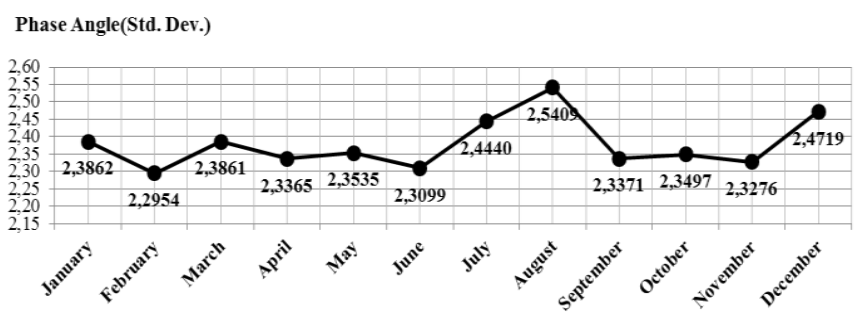

Fig.12. Monthly standard derivations of the voltage angles for case-II

\subsection{Case-III:}

In this case, the dynamic-stochastic OPF model is applied. In this model, all renewable energy sources have uncertainties modeled with Weibull PDFs for each month. The other generation buses are considered same as the standard IEEE 30bus test system. The results obtained from model-3 are represented in Table 7 .

The results are computed monthly for each bus with dynamic-stochastic OPF model which have renewable power plants having uncertainties. The coefficients of the quadratic cost function are also taken zero for the renewable energy sources at this case study since there are no or close to zero fuel costs for renewable power plants in actual in steady-state. But, the costs computed are closer to the real values. The graphic results are also depicted in Fig. 13, 14 and 15.

TABLE VII

THE RESULTS OF CASE-III

\begin{tabular}{|c|c|c|c|c|c|}
\hline \\
\hline Months & $\begin{array}{r}\text { Total } \\
\text { Active } \\
\text { Power, } \\
{[\mathrm{MW}]}\end{array}$ & $\begin{array}{c}\text { Total } \\
\text { Reactive } \\
\text { Power, } \\
\text { [MVAR] }\end{array}$ & $\begin{array}{l}\text { Cost, } \\
{[\$ / h]}\end{array}$ & $\begin{array}{c}\text { Standard } \\
\text { Deviations } \\
\text { of The } \\
\text { Voltage } \\
\text { Magnitudes }\end{array}$ & $\begin{array}{c}\text { Standard } \\
\text { Deviations } \\
\text { of The } \\
\text { Phase } \\
\text { Angles }\end{array}$ \\
\hline January & 261,531 & 30,324 & 391,00 & 0,0166 & 2,2085 \\
\hline February & 234,334 & 30,590 & 310,88 & 0,0158 & 2,0345 \\
\hline March & 260,239 & 32,257 & 309,64 & 0,0162 & 2,2221 \\
\hline April & 234,870 & 10,040 & 297,27 & 0,0148 & 1,9913 \\
\hline May & 246,309 & 17,278 & 404,46 & 0,0158 & 2,1926 \\
\hline June & 242,333 & 23,650 & 359,31 & 0,0158 & 2,0884 \\
\hline July & 272,714 & 31,995 & 361,85 & 0,0168 & 2,3395 \\
\hline August & 290,196 & 30,820 & 435,72 & 0,0171 & 2,3453 \\
\hline September & 249,556 & 23,018 & 307,25 & 0,0145 & 2,1770 \\
\hline October & 242,360 & 20,041 & 265,36 & 0,0146 & 2,0449 \\
\hline November & 247,604 & 25,265 & 368,38 & 0,0159 & 2,1500 \\
\hline \multirow[t]{2}{*}{ December } & 277,794 & 48,549 & 403,73 & 0,0176 & 2,2719 \\
\hline & $\begin{array}{c}3059,84 \\
\text { (total) }\end{array}$ & $\begin{array}{l}323,83 \\
\text { (total) }\end{array}$ & $\begin{array}{c}4214,85 \\
\text { (total) }\end{array}$ & $\begin{array}{c}0,0159 \\
\text { (average) }\end{array}$ & $\begin{array}{c}2,1721 \\
\text { (average) }\end{array}$ \\
\hline
\end{tabular}

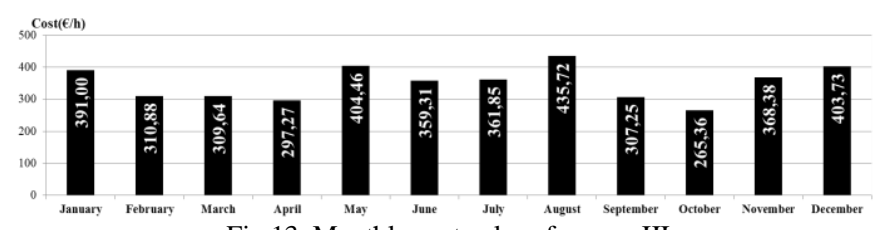

Fig. 13. Monthly cost values for case-III

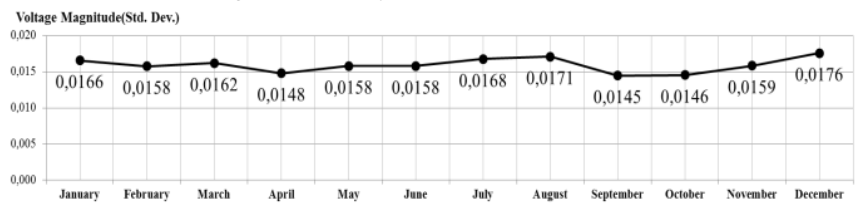

Fig.14. Monthly standard derivations of the voltage magnitudes for case-III

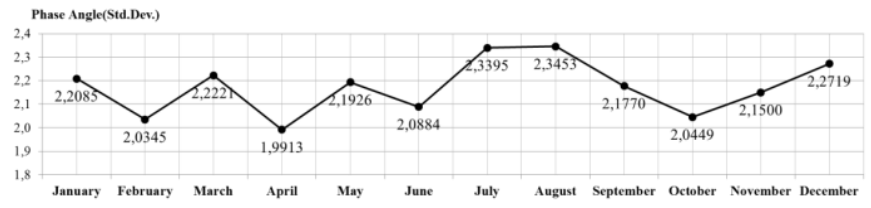

Fig.15. Monthly standard derivations of the voltage angles for case-III

\section{RESULTS AND DISCUSSION}

At the end of the studies, the monthly standard deviations of the voltage magnitudes are specified in Fig. 16. It is observed from the figure that while the voltage magnitudes relatively decrease for some months of Model-2, the values computed at Model-3 is almost the same as the Model-1 which is assumed as a reference. It can be seen that these decreases in Model-2 are caused from inadequacy of the reactive powers supplied to the network by the entire power plants at April and October as observed from Table 6 , since the renewable power plants have been taken constant capacities in this model.

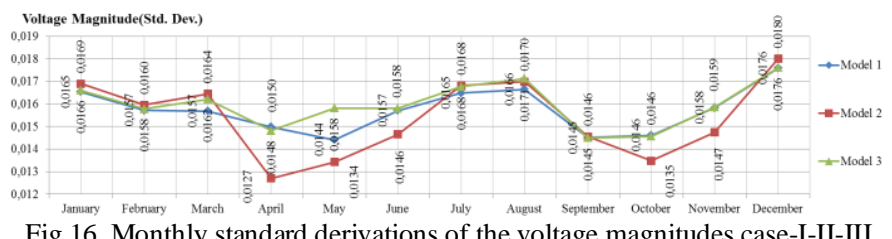

Fig.16. Monthly standard derivations of the voltage magnitudes case-I-II-III

On the other hand, the results are obtained relatively better in Model-3 according to the Model-1 for some months such as March, May and August, since the reactive power support of the power plants to the consumers increase in these months as seen from the tables as well.

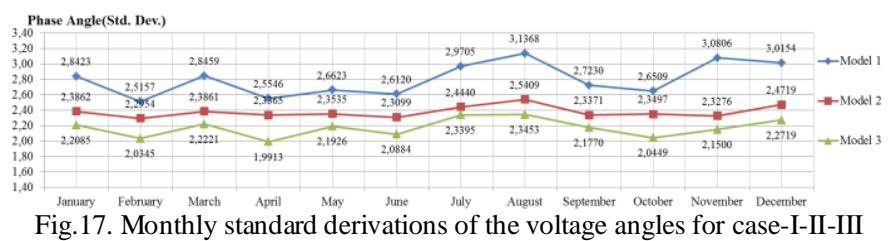

Also, it is seen from the Fig. 17 that the phase angles of the bus voltages decrease in general and they have been more stable when the renewable power plants are integrated to the power system. When the monthly costs are examined, it is normally seen that the costs obtained from Model-1 which involved only IEEE 30-bus system are bigger than the other models which include renewable energy sources. Its maximum and minimum values are computed as $802.05 \$ / \mathrm{h}$ and $618.91 \$ / \mathrm{h}$, respectively. At Model-2, the maximum and minimum values are computed as $236.98 \$ / \mathrm{h}$ and $111.97 \$ / \mathrm{h}$, respectively. They are relatively very small compared to the values obtained from Model-1, since the $\alpha, \beta, \gamma$ coefficients of the cost function are assumed zero for renewable energy sources. These results are not realistic, but they are computed in order to be able to notice the change in Model-3 in this study. They directly follow the load curve, as similar to the Model-1. On the other hand, when the uncertainties are added to the renewable energy sources by using Weibull PDFs in Model-3, the generation costs are obtained more realistic. At this study, their maximum and minimum values are computed as $435.72 \$ / \mathrm{h}$ and $264.36 \$ / \mathrm{h}$, 
respectively. From these results summarized in Table 8, it can be clearly seen that the electric energy generation costs are decreased almost in a half, although both the total active power generation is nearly the same and the voltage and the phase angles are keep their stabilities. In addition, it is provided that the reactive power generation also decreases almost in a half as well in this circumstance.

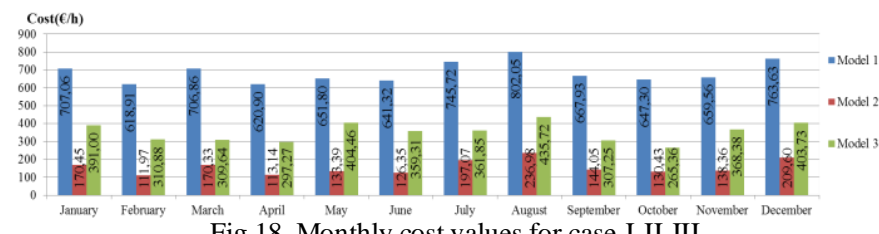

Fig.18. Monthly cost values for case-I-II-III

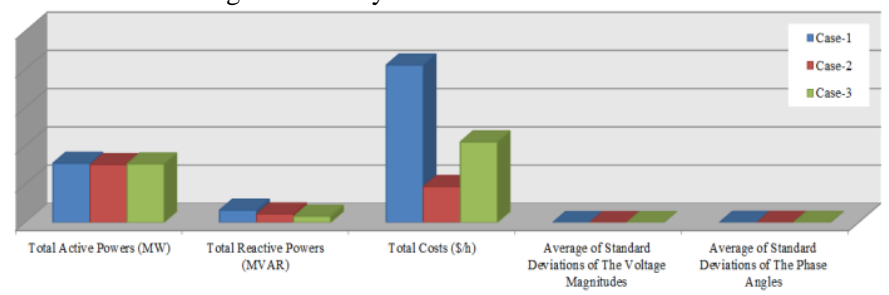

Fig.19. Graphical comparison of the entire results

As a result, the proposed DSOPF analysis which takes into account the uncertainty effects of renewable energy resources as well, clearly shows with the example study that the contribution of integrating the renewable power plants into the power system which includes classic thermal power plants are in important level.

TABLE VIII

COMPARISON OF THE RESULTS OF CASE-I-II-III

\begin{tabular}{|c|c|c|c|c|c|}
\hline & $\begin{array}{c}\text { Total } \\
\text { Active } \\
\text { Powers, } \\
{[\mathbf{M W}]}\end{array}$ & $\begin{array}{c}\text { Total } \\
\text { Reactive } \\
\text { Powers, } \\
{[\text { [MVAR] }}\end{array}$ & $\begin{array}{c}\text { Total } \\
\text { Costs, } \\
\text { [\$/h] }\end{array}$ & $\begin{array}{c}\text { Average } \\
\text { of } \\
\text { Standard } \\
\text { Deviations } \\
\text { of the } \\
\text { Voltage } \\
\text { Magnitudes }\end{array}$ & $\begin{array}{c}\text { Average } \\
\text { of } \\
\text { Standard } \\
\text { Deviations } \\
\text { of the } \\
\text { Phase } \\
\text { Angles }\end{array}$ \\
\hline Case-1 & 3096,95 & 643,43 & 8233,04 & 0,0157 & 2,8000 \\
\hline Case-2 & 3030,59 & 450,77 & 1882,12 & 0,0153 & 2,3782 \\
\hline Case-3 & 3059,84 & 323,83 & 4214,85 & 0,0159 & 2,1721 \\
\hline
\end{tabular}

\section{CONCLUSION}

The effect of uncertain renewable energy sources integrated into a specific area of Turkey electricity power system on the static voltage stability is simulated by using DSOPF analysis in this study. DSOPF analyses combined Weibull PDF throughout a year is chosen in order to taking into account uncertainty effect of the renewable energy resources. Also, the IEEE 30bus system is adapted with the method proposed in the study to the Turkish electricity system by using 2015 Turkey real and reactive load curves, as different from the literature. The analyses are performed on three models for comparison with each other. At the end of the proposed study, it is observed that the integration of realistic renewable energy sources with uncertainty into the Turkey electricity power system decreases approximately $50 \%$ both the yearly total generation cost and the reactive power generation, without changing the current active power generation. In this condition, it can be said that the static voltage stability of the power system is became more stable due to increase the reactive power margin.

\section{REFERENCES}

[1] The Economist, "European Utilities, How to Lose Half A Trillion Euros",October15th2013,https://www.economist.com/news/briefing/21 587782-europes-electricity-providers-face-existential-threat-how-losehalf-trillion-euros

[2] IEA Renewables 2017, London, October $4^{\text {th }} 2017$, https://www.iea.org/media/publications/mtrmr/Renewables2017Launch Presentation.pdf

[3] REN21 Renewable 2017 Global Status Report, http://www.ren21.net/wp-content/uploads/2017/06/17-

8399_GSR_2017_Full_Report_0621_Opt.pdfiology, January２013, pp.1-11.

[4] Electromagnetic Yenilenebilir Enerji Genel Müdürlüğü (General Directorate Of Renewable Energy), http://www.eie. gov.tr/anasayfa2.aspx.

[5] J. Liang, G.K. Venayagamoorthy, R.G. Harley, "Wide-area measurement based dynamic stochastic optimal power flow control for smart grids with high variability and uncertainty," IEEE Transactions on Smart Grid, vol.3, no.1, pp.59-69, 2012.

[6] S. Gill, I. Kockar, G.W. Ault, "Dynamic Optimal Power Flow For Active Distribution Networks", IEEE Transactions On Power Apparatus And Systems, vol.29P, issue.1, pp.121-131, 2014.

[7] C. Wei, Y. Fu, Z. Li, Y. Jiang, "Optimal DG Penetration Rate Planning Based On S-OPF In Active Distribution Network," Neurocomputing, vol.174, pp.514-521, 2016.

[8] G. Sun, Y. Li, S. Chen, Z. Wei, S. Chen, H. Zang, "Dynamic Stochastic Optimal Power Flow Of Wind Power And The Electric Vehicle Integrated Power System Considering Temporal Spatial Characteristics", Journal of Renewable and Sustainable Energy, vol.8, issue. 5, 2016.

[9] W. Bai, D. Lee, K. Lee, "Stochastic Dynamic Optimal Power Flow Integrated with Wind Energy Using Generalized Dynamic Factor Model", IFAC-Papers On-Line, vol.49, issue.27, pp.129-134, 2016.

[10] W. Bai, "Stochastic Dynamic Optimal Power Flow Under The Variability Of Renewable Energy With Modern Heuristic Optimization Techniques", PhD. Thesis, Baylor University, Waco, Texas, 2017.

[11] J. Carpentier, "Contribution a l'etude du dispatching economique", Bulletin de la Societe Francaise des Electriciens, vol.3, iss. 1, pp.431-447, 1962.

[12] B. Ghaddar, J. Marecek, M. Mevissen, "Optimal Power Flow As A Polynomial Optimization Problem", IEEE Transactions on Power Systems, vol.31, issue.1, pp.539-546, 2016.

[13] J. Lin, V.O. Li, K.C. Leung, A.Y. Lam, "Optimal Power Flow With Power Flow Routers", IEEE Transactions on Power Systems, vol.32, issue.1, pp.531-543, 2017.

[14] S. Frank, I. Steponavice, S. Rebennack, "Optimal Power Flow: A Bibliographic Survey I”, Energy Systems, vol.3, issue.3, pp.221-258, 2012.

[15] K.C. Almeida, A. Kocholik, "Solving Ill-Posed Optimal Power Flow Problems Via Fritz-John Optimality Conditions", IEEE Transactions on Power Systems, vol.31, issue.6, pp.4913-4922, 2016.

[16] A.D. Chandekar, D. Subroto, "A Review on Optimal Power Flow Solutions under Variable Load", International Journal of Advanced Research in Electrical, Electronics and Instrumentation Engineering, vol.4, issue. 1, 2015.

[17] A.M. Shaheen, R.A. El-Sehiemy, S.M. Farrag, "Solving Multi Objective Optimal Power Flow Problem Via Forced Initialised Differential Evolution Algorithm", IET Generation, Transmission \& Distribution, vol.10, issue.7, pp.1634-1647, 2016.

[18] T. Niknam, M.R. Narimani, M. Jabbari, "Dynamic Optimal Power Flow Using Hybrid Particle Swarm Optimization And Simulated Annealing", International Transactions on Electrical Energy Systems, vol.23, issue.7, pp.975-1001, 2013.

[19] Y. Xu, J. Ma, Z.Y. Dong, D.J. Hill, "Robust Transient StabilityConstrained Optimal Power Flow With Uncertain Dynamic Loads", IEEE Transactions on Smart Grid, vol.8, issue.4, pp.1911-1921, 2017.

[20] Y. Xu, Z.Y. Dong, Z. Xu, R. Zhang, K.P. Wong, "Power System Transient Stability-Constrained Optimal Power Flow: A Comprehensive Review", In IEEE Power and Energy Society General Meeting, pp.1-7, 2012.

[21] M.M. Bhaskar, M. Srinivas, M. Sydulu, "Security Constraint Optimal Power Flow (SCOPF)-A Comprehensive Survey", International Journal of Computer Applications, vol.11, issue.6, pp.42-52, 2010. 
[22] M. Lubin, Y. Dvorkin, "A Robust Approach to Chance Constrained Optimal Power Flow with Renewable Generation", IEEE Transactions on Power Systems, vol.31, issue.5, pp.3840-3849, 2016.

[23] A. Vaccaro, C.A. Cañizares, "An Affine Arithmetic-Based Framework For Uncertain Power Flow And Optimal Power Flow Studies", IEEE Transactions on Power Systems, vol.32, issue.1, pp.274-288, 2017.

[24] M. Bazrafshan, N. Gatsis, "Decentralized Stochastic Optimal Power Flow In Radial Networks With Distributed Generation", IEEE Transactions on Smart Grid, vol.8, issue.2, pp.787-801, 2017.

[25] J. Gong, D. Xie, C. Jiang, Y. Zhang, “A New Solution For Stochastic Optimal Power Flow: Combining Limit Relaxation With Iterative Learning Control", Journal of Electrical Engineering and Technology, vol.9, issue.1, pp.80-89, 2014.

[26] H. Zhang, P. Li, "Probabilistic Analysis For Optimal Power Flow Under Uncertainty", IET Generation, Transmission \& Distribution, vol.4, issue. 5, pp.553-561, 2010.

[27] A. Schellenberg, W. Rosehart, J. Aguado, "Cumulant-Based Probabilistic Optimal Power Flow (P-OPF) With Gaussian And Gamma Distributions", IEEE Transactions on Power Systems, vol.20, issue.2, pp.773-781, 2005.

[28] G. Verbic, C.A. Canizares, "Probabilistic Optimal Power Flow In Electricity Markets Based On A Two-Point Estimate Method", IEEE transactions on Power Systems, vol.21, issue.4, pp.1883-1893, 2006.

[29] D. Ke, C.Y. Chung, Y. Sun, "A Novel Probabilistic Optimal Power Flow Model With Uncertain Wind Power Generation Described By Customized Gaussian Mixture Model", IEEE Transactions on Sustainable Energy, vol.7, issue.1, pp.200-212, 2016.

[30] M. Ou, Y. Xue, X.P. Zhang, "Iterative DC Optimal Power Flow Considering Transmission Network Loss", Electric Power Components and Systems, vol.44, issue.9, pp.955-965, 2016.

[31] T. Akbari, M.T. Bina, "Linear Approximated Formulation Of AC Optimal Power Flow Using Binary Discretisation", IET Generation, Transmission \& Distribution, vol.10, issue.5, pp.1117-1123, 2016.

[32] W. Feng, A. Le Tuan, L.B. Tjernberg, A. Mannikoff, A. Bergman, "A New Approach For Benefit Evaluation Of Multiterminal VSC-HVDC Using A Proposed Mixed AC/DC Optimal Power Flow", IEEE Transactions on Power Delivery, vol.29, issue.1, pp.432-443, 2014.

[33] www.washington.edu,https://www2.ee.washington.edu/research/pstca/p f30/pg_tca30bus.htm.

[34] https://www.teias.gov.tr/tr/yayinlar-raporlar/sektor-raporlari/isletmefaaliyetleri-raporlari/2015-yili-isletme-faaliyetleri-raporu.

[35] P.P. Biswas, P.N. Suganthan, G.A.J. Amaratunga, "Optimal power flow solutions incorporating stochastic wind and solar Power", Energy Conversion and Management, vol.148, pp.1994-1207, 2017.

[36] F. Süzek, "Türkiye Rüzgâr Enerji Potansiyelinin Belirlenmesi," İstanbul, 2007.

\section{BIOGRAPHIES}

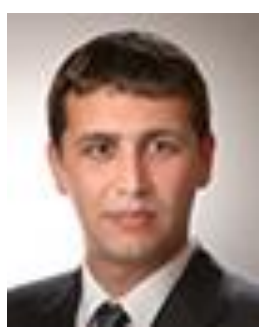

BASAR BAYDAR graduated from Department of Electrical and Electronics Engineering, Osmangazi University, Eskisehir, Turkey in 2014 and working as an Electrical Engineer at Baskent Electrical Distribution Company, EnerjiSA, Ankara, Turkey. He is currently a student of M.Sc. degree in Electrical and Electronics Engineering Department, Gazi University, Ankara, Turkey. His main research interests and subjects are high voltage engineering, power systems, smart grids and renewable energy sources.

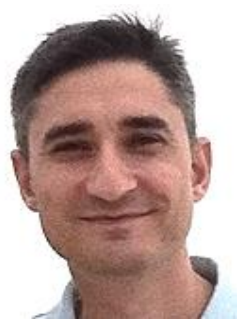

HALUK GOZDE received the B.Sc. degree in Electrical and Electronics Engineering from Karadeniz Technical University, Trabzon, Turkey, in 1997, and the M.Sc. and the Ph.D. degrees in Electrical and Electronics Engineering from Gazi University, Ankara, Turkey, in 2004 and 2010, respectively. Then, he is an Assoc.Prof. of the electrical and electronics engineering in National Defense University since 2016. His main research area consists of power system dynamics and control, artificial intelligence-based control methods, and swarm intelligence-based optimization algorithms.

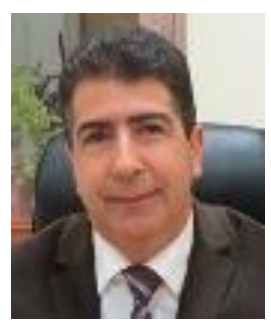

M. CENGIZ TAPLAMACIOGLU graduated from Department of Electrical and Electronics Engineering, Gazi University, Ankara, Turkey. He received the degrees of M.S. degree in Industrial Engineering from Gazi University in 1985 and in Electrical and Electronics Engineering from Middle East Technical University and received the Ph.D. degree in Electrical, Electronics and System Engineering from University of Wales (Cardiff, UK). $\mathrm{He}$ is a Professor of the Electrical and Electronics Engineering since 2000 and the Chairman of the Department of Electrical and Electronics Engineering in Gazi University between 2001 2012. His research interests and subjects are high voltage engineering, corona discharge and modeling, electrical field computation, measurement and modeling techniques, optical HV measurement techniques, power systems control and protection, and lighting techniques. 